\title{
Birth by cesarean section and mood disorders among adolescents of a birth cohort study in northern Brazil
}

\author{
S.J.D.C. Coelho ${ }^{1 \oplus \bowtie}$, V.M.F. Simões ${ }^{2 \oplus}$, R.F.L. Batista ${ }^{2 \oplus}$, C.C.C. Ribeiro ${ }^{2 \oplus}$, Z.C. Lamy ${ }^{2 \oplus}$ \\ F. Lamy-Filho ${ }^{2 \oplus}$, C.A. Carvalho ${ }^{3 \oplus}$, P.C.A.F. Viola ${ }^{4 \oplus}$, R.C.S. Queiroz ${ }^{2 \oplus}$, A.A. Ferraro ${ }^{5 \oplus}$, and \\ H. Bettiol ${ }^{6}$
}

${ }^{1}$ Programa de Pós-Graduação em Saúde Coletiva, Universidade Federal do Maranhão, São Luís, MA, Brasil

${ }^{2}$ Departamento de Saúde Pública, Universidade Federal do Maranhão, São Luís, MA, Brasil

${ }^{3}$ Pós-Graduação em Saúde Coletiva, Universidade Federal do Maranhão, São Luís, MA, Brasil

${ }^{4}$ Departamento de Nutrição, Universidade Federal do Piauí, Teresina, PI, Brasil

${ }^{5}$ Departamento de Pediatria, Faculdade de Medicina, Universidade de São Paulo, São Paulo, SP, Brasil

${ }^{6}$ Departamento de Puericultura e Pediatria, Faculdade de Medicina, Universidade de São Paulo, Ribeirão Preto, SP, Brasil

\begin{abstract}
The increasing number of cesarean sections worldwide has encouraged research on the long-term effects of this birth type on the offspring's mental health. The objective of this study was to investigate whether there is an association between birth by cesarean section and the development of mood disorders (depression and bipolar disorders) in adolescents. A cohort study was carried out with 1603 adolescents from 18 to 19 years old who participated in the third phase of a birth cohort study in São Luís, MA, in 2016. Information on birth type and weight, prematurity, mother's age and schooling, parity, marital status, and smoking behavior during pregnancy, were collected at birth. The study outcomes were depression, bipolar disorder, and "mood disorder" construct. A Directed Acyclic Graph (DAG) was developed to select the variables for minimal adjustment for confounding and collision bias. Associations were estimated through propensity score weighting using a two-step estimation model, and confounders for cesarean birth were used in the predictive model. There was no significant association in the relationship between birth type and depression ( $95 \% \mathrm{Cl}:-0.037$ to $0.017 ; \mathrm{P}=0.47$ ), bipolar disorder ( $95 \% \mathrm{Cl}:-0.019$ to $0.045 ; \mathrm{P}=0.43)$, and mood disorder $(95 \% \mathrm{Cl}:-0.033$ to $0.042 ; \mathrm{P}=0.80)$ in adolescents of both sexes. Birth by cesarean section was not associated with the development of mood disorders in adolescents.
\end{abstract}

Key words: Cesarean section; Bipolar disorder; Depressive disorder; Mood disorders; Adolescent behavior

\section{Introduction}

Birth by cesarean section is a life-saving surgical procedure in cases with maternal-fetal complications. Nevertheless, the increasing number of cesarean sections performed in several countries worldwide has encouraged the study of their consequences on the offspring's mental health (1). Recent estimates show that the global average rate of cesarean sections ranges from $6-27.2 \%$ in areas with lower and higher socioeconomic development, respectively. Cesarean section rates were found to be as high as $40.5 \%$ in Latin America and the Caribbean and $55.6 \%$ in Brazil in 2014 (2).

Studies have shown that cesarean birth is associated with alterations in the child's intestinal bacterial microbiome, loss of benefits resulting from exposure to deliveryinduced hormonal and immunological physiological changes, and neurodevelopmental disorders (3-6). These complications could explain the increased risk of obesity $(7,8)$, allergic and respiratory diseases (9), and Type 1 diabetes mellitus (10) in children delivered by cesarean section. The literature has also indicated a higher risk of autism spectrum disorder, attention deficit and hyperactivity disorder $(11,12)$, and bipolar mood disorder in individuals delivered by cesarean procedures $(13,14)$.

Depression and bipolar disorders are mood disorders with complex and poorly understood multifactorial etiology that result from a combination of genetic, environmental, psychological, and physiological factors. Depression is characterized by loss of interest or pleasure in activities and sad mood during most of the day, as well as changes in sleep, appetite, concentration, psychomotricity, among others. Bipolar mood disorder is characterized by mood or affection pathological alterations, which may vary from hypomania or mania (extreme elation) to severe depression. Such disorders can begin even in childhood or 
adolescence and persist into adulthood, causing adverse psychosocial and neurobiological consequences (15), which are risk factors for suicidal behavior in adolescence (16). The overall prevalence of depression and bipolar disorder in adolescents is $2.6 \%$ (17) and $1.8 \%$ (16), respectively. It is known that the genetic component influences the etiology of these mood disorders (18), but little is known about how perinatal environmental factors could interact with the individual's genetics, making them susceptible to illness.

In a Finnish case-control study, Chudal et al. (13) investigated perinatal factors and the risk of developing bipolar disorder. The authors found an association between bipolar disorder and elective cesarean births with an odds ratio of 2.5. In a Swedish cohort study, O'Neill et al. (14) investigated the association between the delivery type and the development of mental illness in the offspring. The authors found an increased risk of bipolar disorder in individuals born by elective cesarean section in the adjusted model; however, the statistical data analysis with paired-to-sibling Cox regression model no longer indicated a significant association.

In addition to the lack of consensus in the literature on this topic, there has been an increasing trend of cesarean section procedures worldwide. Even a slight increase in the risk of mood disorder development due to cesarean birth $(13,14,19)$ could significantly burden public healthcare systems. This study aimed to evaluate the association between birth by cesarean section and the development of mood disorders (depression and bipolar disorders) in adolescents, using a more robust method of analysis in a population-based birth cohort.

\section{Material and Methods}

\section{Study design and population}

This was a longitudinal study with data collected from a birth cohort study in the city of São Luís, MA, Brazil. The cohort was initiated in $1997 / 98$ as part of the RPS research consortium with the project entitled "Determinants along the life cycle of obesity, precursors of chronic diseases, human capital and mental health: a contribution of Brazilian birth cohorts to SUS [Brazilian healthcare system]", carried out by the Federal University of Maranhão, the Ribeirão Preto Medical School at University of São Paulo, and the Federal University of Pelotas.

This study used data from adolescents who were born in the city of São Luís, MA, in 1997, of both sexes, in public and private maternity hospitals and hospitals with maternity services (20) and who were followed up in the third stage of the cohort study.

The third phase of the study took place in 2016 when the adolescents were from 18 to 19 years of age. All participants who were included in the first phase of the cohort were contacted to participate in the third follow-up, totaling 684 adolescents. In the third phase, to increase the statistical power of the sample and minimize future dropouts, the cohort was opened to include other individuals born in São Luís, MA, in the year of 1997. First, additional individuals were included through a draw using the Information System on Live Births (http://sinasc.saude. gov.br/); second, volunteers were recruited in schools, universities, and on social media, with a final study population of 1831 adolescents. Thus, the sample evaluated in the third phase of the study was composed of 684 adolescents from the original cohort and 1831 added in 2016, totaling 2515 individuals. Of these, after exclusion of unreported perinatal data and forceps birth delivery entries, the final sample of the present study was 1603 adolescents. More details on the methodology of this study can be found in Simões et al. (21).

The study complied with the Resolution number 466/ 2012 of the National Health Board and Operational Standard 001/2013/CNS and was approved by the Ethics Committee in Research of the University Hospital of the Federal University of Maranhão.

\section{Data collection and study variables}

Data were collected by trained health sciences' graduate and undergraduate students. All participants signed an Informed Consent Term. Maternal and perinatal sociodemographic data of the adolescents were obtained through the Birth Questionnaire, which was applied retrospectively to mothers during the third phase of the cohort study. The following variables were collected: delivery type (vaginal, cesarean section), low birth weight $(<2,500 \mathrm{~g}$ according to $\mathrm{WHO}$, yes, no), preterm birth (gestational age $<37$ weeks, yes, no), mother's age $(<20,20$ to $34, \geqslant 35$ years), parity (primiparous, multiparous), mother's schooling (never attended school, elementary school, high school, technical degree, college, specialization, master's degree), marital status (with, without partner), and maternal smoking during pregnancy (yes, no). The delivery type was the main explanatory independent variable used dichotomously.

This study used information collected through structured interviews with adolescents on sociodemographic, economic, and life-style aspects during the third phase of the study, when they were $18 / 19$ years of age. The following variables were obtained: sex (male, female), selfreported skin color (white, black, brown/mixed, yellow, indigenous), currently studying (yes, no), religion or cult (yes, no), divorced parents (yes, no), current family income in minimum wages $(\leqslant 1,2-4,5-8,9-12, \geqslant 13)$, and adolescent's current smoking habit (yes, no). The use of alcoholic beverages by the adolescents was classified as low- or high-risk through the Alcohol Use Disorder Identification Test (AUDIT) (22).

The outcome variables of this study were depressive disorder, bipolar disorder, and the "mood disorder" construct in adolescents. This construct was formed from the following variables: current or recurrent major depressive episode (depressive disorder) and episode of hypo- 
mania or mania (bipolar disorder), which were evaluated through the M.I.N.I. (Mini International Neuropsychiatric Interview - Brazilian version 5.0.0) questionnaire, which can be used by clinicians after training. The M.I.N.I. was applied by two clinical psychologists who were trained previously. An adolescent who presented at least one of these episodes was diagnosed with a mood disorder. The outcome variables were dichotomized (presence, absence) for statistical analysis.

The M.I.N.I questionnaire is a brief standardized diagnostic interview compatible with the diagnostic criteria of DSM IV (Diagnostic and Statistical Manual of Mental Disorders - 4th Edition) and the International Classification of Diseases, 10th revision (CID-10). It is a validated diagnostic instrument designed to assess current and previous mental disorders with satisfactory reliability indexes. The M.I.N.I questionnaire can be used in clinical practice and research (23).

\section{Theoretical model}

A theoretical model was developed to investigate the association between cesarean birth and the presence of mood disorders in adolescence through Directed Acyclic Graphs (DAG). DAGs are diagrams that encode qualitative hypotheses on causal processes provided by data through non-parametric structural equation models. A graph is directed when all edges are represented by a single arrow, assuming that causality flows in only one direction, and is acyclic when no connection between variables forms a closed circuit (24). The Dagitty program (public domain, available at http://www.dagitty.net/) was used to create the graphic model (25).

After creation of the DAG (Figure 1), the program applied algorithms based on the "back door" principle, which identifies non-causal pathways that may suggest spurious associations. In addition, the program established the minimum set of variables necessary for adjustment, with the purpose of identifying confounding bias, avoiding collision bias and also avoiding the inclusion of mediators in the adjustment $(26,27)$. The variables suggested by the DAG for minimum adjustment were as follows: preterm birth, maternal parity, smoking during pregnancy, mother's schooling, and age. The adolescent's genetics and microbiome were non-measured variables in this graphical model.

\section{Data processing and statistical analysis}

The data were exported from REDcap ${ }^{\circledR}$ (www.projectredcap.org) into Excel spreadsheets for analysis in the Stata/MP $14.0^{\circledR}$ Program (StataCorp, LLC, USA). Categorical variables are described as absolute and relative frequencies.

The hypothesis of this study was that cesarean birth is associated with depression, bipolar disorder, or mood disorder in adolescence. A graphical and counterfactual approach was used to test the hypothesis using a propensity score weighting estimation method, which is the

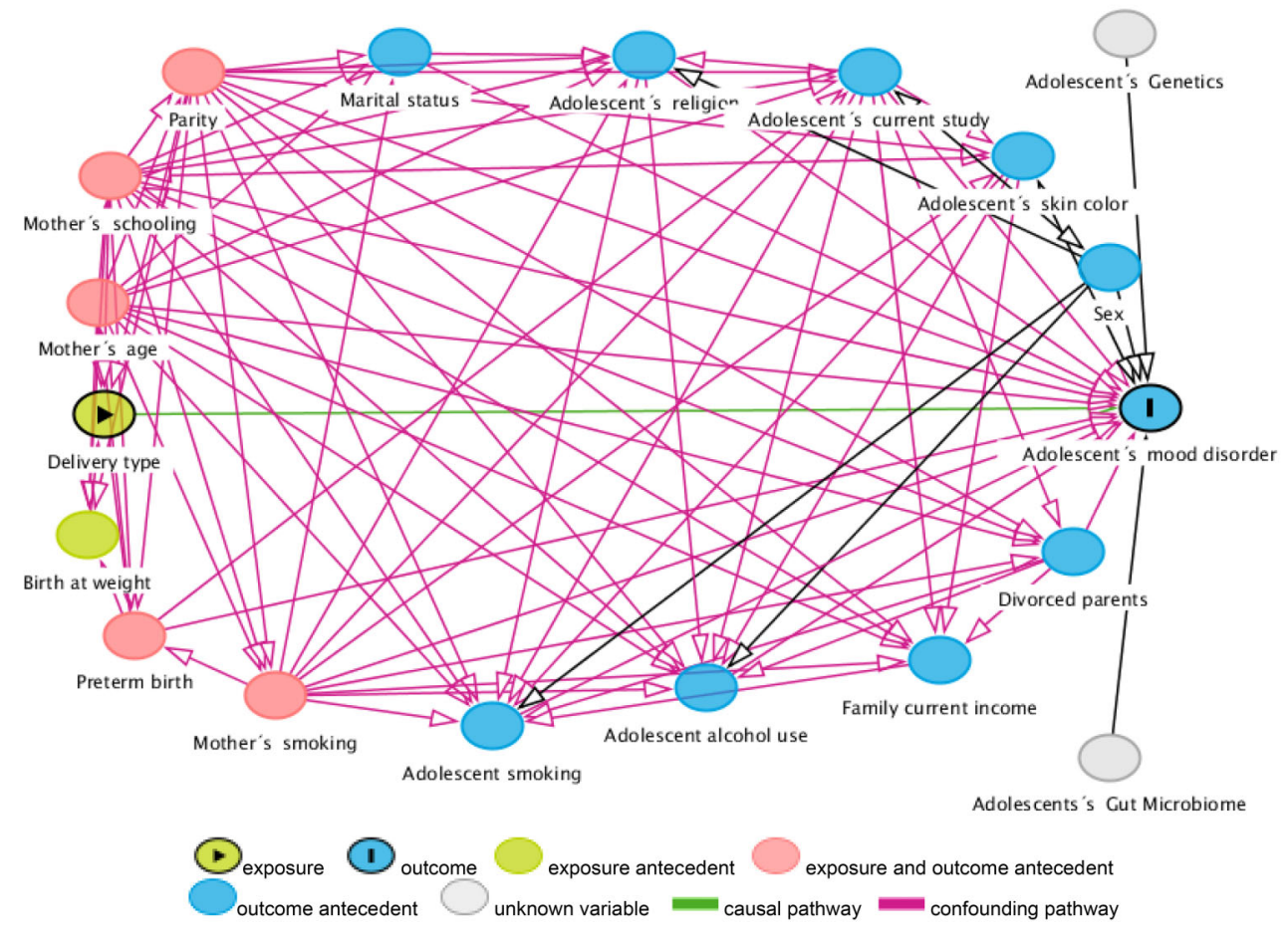

Figure 1. Directed Acyclic Graph: theoretical model of causal association between childbirth type and mood disorder in adolescents. 
conditional probability of receiving the treatment (born by cesarean section) as a function of exposure predictor variables (28). Hence, individuals who were more likely to be selected to receive treatment had a lower weight, while those who were less likely to receive treatment had a greater weight (29).

One of the assumptions for causal inference is interchangeability, a condition required for a balanced distribution of adjustment variables between exposed and non-exposed groups to avoid selection bias (30). Interchangeability occurs when there is an effective balance between the variables predicting the group outcomes. Absolute standardized mean differences of predictor variables between the groups and variance ratios were determined. An absolute standardized difference between the means lower than 0.1 standard deviation was considered as having good interchangeability, (31) whereas variables with variance ratio between 0.8 and 1.2 were considered as balanced (32). A stratified analysis by adolescent's sex was also carried out due to differences in mood disorders' prevalence among study participants (15).

The teffects ipw package of the Stata/MP $14.0^{\circledR}$ Program was used to determine the average treatment effect (ATE) on the population using the minimal adjustment of variables suggested by the DAG. The ATE calculation was possible because there was a good common support zone between the exposed and non-exposed groups. As observed in the boxplot graph shown in Figure 2 , there was an effective match between the groups. A $5 \%$ significance level was considered.

\section{Results}

A total of 1603 adolescents were evaluated in 2016 and $50.2 \%$ were males, $62.4 \%$ self-reported having brown/mixed skin color, and $59.9 \%$ had a family income between 1 and 4 minimum wages. As for the use of psychoactive substances, $91.7 \%$ of the adolescents did not smoke and $19.0 \%$ had high-risk alcohol consumption behavior. About perinatal characteristics of adolescents,

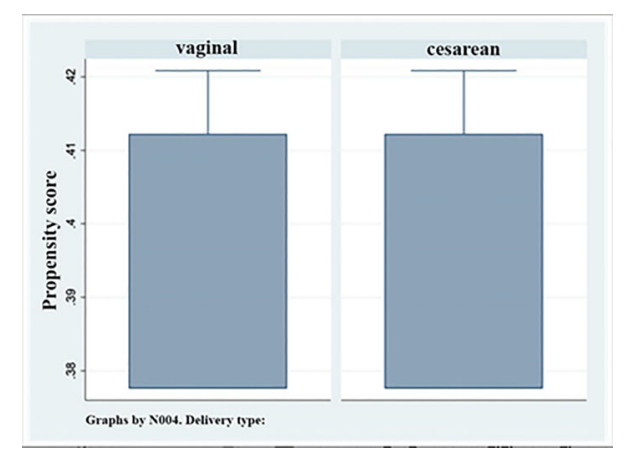

Figure 2. Propensity score boxplot by delivery type. Data are reported as means and standard deviations.
$43.7 \%$ were born by cesarean delivery, $8.9 \%$ had low-birth weight, and $10.4 \%$ had preterm birth. At birth, $71 \%$ of the adolescents' mothers were aged between 20 and 34 years, $53.5 \%$ had completed high school, and $79.9 \%$ of them had a partner. Other perinatal, sociodemographic, and economic characteristics of adolescents and maternal socioeconomic conditions are shown in Table $1 \mathrm{~A}$ and $\mathrm{B}$.

Depressive disorder, bipolar disorder, and mood disorder were identified in $7.4,9.7$, and $15.2 \%$ of adolescents, respectively. There was no significant association between these mental conditions and the delivery type (cesarean section or vaginal) (Table 2).

Adjustment variables (preterm birth, parity, smoking during pregnancy, mother's schooling, and age) were well-balanced after weighting with propensity score, indicating a good interchangeability between the exposed (born by cesarean section) and unexposed groups. For these variables, a weighted value of less than 0.1 was obtained for the difference between the standardized means, while variance ratios ranged between 0.8 and 1.2 (Table 3).

As seen in Figure 2, the boxplot graph of the propensity score showed a good common support zone in both groups. These results indicated that there was a good match between the cesarean section and vaginal delivery groups; therefore, the ATE on the population could be successfully calculated.

The ATE calculation indicated no significant difference in the presence of depressive disorder, bipolar disorder, and mood disorder among adolescents of both sexes born by cesarean section (Table 4).

\section{Discussion}

Studies have addressed the association between cesarean birth and the development of mood disorders, such as depression and bipolar disorder, which are conditions with complex etiology yet to be completely understood $(13,14,19,33)$. The present study investigated whether cesarean section was associated with the development of such disorders in adolescence. The results reported herein demonstrate that there was no association between the birth delivery type and the presence of mood disorders in this adolescent population, even after stratification by sex. Additionally, we highlight that the prevalence of mental disorders among adolescents was high, pointing to a public health problem that can be explained by the socioeconomic determinants of Maranhão, one of the poorest regions in Brazil (34).

There was no association between cesarean birth and the development of depression and bipolar disorder in adolescents of both sexes. Nevertheless, a case-control study $(n=2,143)$ carried out in Finland by Chudal et al. (13) reported a 2.5 higher chance of bipolar disorder $(95 \% \mathrm{Cl}$ : 1.32-4.78) in individuals born by elective cesarean section. The mean age at disease onset in the Finnish 
study was 17 years, similar to that of our study. In another study, depression and bipolar disorder among adolescents had prevalence rates of 7.74 and $9.73 \%$, respectively, which were higher than those in Finland $(6.5 \%$ for depression (35) and only $0.65 \%$ for bipolar disorder (36)). Among the confounding factors, the mother's age and schooling, parity, and smoking during pregnancy were adjusted in both studies.

In a cohort study in Sweden ( $n=6,260)$, O'Neill et al. (14) found a 1.16-fold increased risk $(95 \% \mathrm{Cl}$ : $1.03-1.33)$ for bipolar disorder in individuals born by elective cesarean section in the fully adjusted model. However, after analysis by paired-to-sibling Cox regression model using healthy sibling controls, the association with elective cesarean sections was no longer observed. In Sweden, the prevalence of bipolar disorder is $2.4 \%$, with an average onset age of 18 years (37). The percentage of cesarean birth deliveries in this study $(43.67 \%)$ was almost two-fold that of

Table 1. Perinatal, sociodemographic, and economic characteristics of adolescents and maternal socioeconomic conditions.

\begin{tabular}{|c|c|}
\hline A. Perinatal variables (1997) & $(n, \%)$ \\
\hline \multicolumn{2}{|l|}{ Delivery type } \\
\hline Vaginal & $903(56.3)$ \\
\hline Cesarean section & $700(43.7)$ \\
\hline \multicolumn{2}{|l|}{ Low birth weight } \\
\hline No & $1459(91.0)$ \\
\hline Yes & $144(9.0)$ \\
\hline \multicolumn{2}{|l|}{ Preterm birth } \\
\hline No & $1429(89.1)$ \\
\hline Yes & $167(10.4)$ \\
\hline Not reported & $7(0.4)$ \\
\hline \multicolumn{2}{|l|}{ Parity } \\
\hline Primiparous & $720(44.9)$ \\
\hline Multiparous & $883(55.1)$ \\
\hline \multicolumn{2}{|l|}{ Mother's age (years) } \\
\hline$<20$ & $326(20.3)$ \\
\hline $20-34$ & $1138(71.0)$ \\
\hline$\geqslant 35$ & $139(8.7)$ \\
\hline \multicolumn{2}{|l|}{ Maternal schooling } \\
\hline Never attended school & $15(0.9)$ \\
\hline Elementary School & $610(38.0)$ \\
\hline High School & $858(53.5)$ \\
\hline Technical Degree or Integrated High School & $31(1.9)$ \\
\hline College & $76(4.7)$ \\
\hline Specialization/Residency & $8(0.5)$ \\
\hline Master's degree & $3(0.2)$ \\
\hline Not Reported & $2(0.1)$ \\
\hline \multicolumn{2}{|l|}{ Maternal marital status } \\
\hline With partner & $1281(79.9)$ \\
\hline Without partner & $322(20.1)$ \\
\hline \multicolumn{2}{|l|}{ Smoking during pregnancy } \\
\hline No & $1534(96.0)$ \\
\hline Yes & $64(4.0)$ \\
\hline Not Reported & $5(0.3)$ \\
\hline Total & $1603(100.0)$ \\
\hline
\end{tabular}

Table 1. Continued

\begin{tabular}{lc}
\hline B. Sociodemographic and economic variables (2016) & \\
\hline Sex & \\
Male & $806(50.3)$ \\
Female & $797(49.7)$ \\
Skin color & \\
Brown/Mixed & $1001(62.4)$ \\
White & $338(21.1)$ \\
Black & $264(16.5)$ \\
Currently studying & \\
Yes & $1185(73.9)$ \\
No & $418(26.1)$ \\
Family income (minimum wage) & \\
$\leqslant 1$ & $320(20.0)$ \\
$>1 \leqslant 4$ & $961(59.9)$ \\
$>4 \leqslant 8$ & $213(13.3)$ \\
$>8 \leqslant 12$ & $55(3.4)$ \\
$>12$ & $54(3.4)$ \\
Religion & \\
Yes & $1143(71.3)$ \\
No & $460(28.7)$ \\
Divorced parents & \\
No & $866(54.0)$ \\
Yes & $737(46.0)$ \\
Smoking & \\
No & $1470(91.7)$ \\
Yes & $133(8.3)$ \\
Alcohol use & $1297(80.9)$ \\
Low risk & $306(19.1)$ \\
High risk & $1603(100.00)$ \\
Total & \\
\hline
\end{tabular}

Data was collected in São Luís, MA, Brazil, in 1997 and 2016.

Europe, where Finland and Sweden are located, with prevalence rates varying from 11.1 to $22.4 \%$ (2).

Chudal et al. (13) and O'Neill et al. (14) differentiated elective cesarean birth delivery from emergency cesarean birth and found a bipolar disorder development risk with the former. However, the disease risk did not remain after pairing for healthy sibling controls in the Swedish study. These findings corroborate the hypothesis that the previously found association was probably caused by residual confounding factors, for instance, maternal-fetal medical complications that required elective cesarean section, as well as unknown genetic and family environmental factors. Therefore, an association between cesarean delivery and bipolar disorder was not supported in that population, nor was it in the population of the present study.

In addition to formal medical indications, elective caesarean sections may be required by mothers who are anxious, depressed, have dysfunctional personality traits, or low social support. Such characteristics may contribute to an increased risk of development of mood disorders in the offspring due to hereditary and behavioral genetic factors in the family environment $(13,38)$. In case 
Table 2. Prevalence of mood disorders by delivery type in adolescents.

\begin{tabular}{lcccc}
\hline Variable & Total $(\mathrm{n}, \%)$ & Vaginal $(\mathrm{n}, \%)$ & C-section $(\mathrm{n}, \%)$ & P-value \\
\hline Depressive disorder & & & & \\
$\quad$ Absent & $1479(92.3)$ & $831(92.0)$ & $648(92.6)$ & \\
$\quad$ Present & $124(7.7)$ & $72(8.0)$ & $52(7.4)$ & 0.685 \\
Bipolar disorder & & & & \\
Absent & $1447(90.3)$ & $818(90.6)$ & $629(89.9)$ & 0.625 \\
Present & $156(9.7)$ & $85(9.4)$ & $71(10.1)$ & \\
Mood disorder & & & & \\
$\quad$ Absent & $1359(84.8)$ & $766(84.8)$ & $593(84.7)$ & 0.950 \\
Present & $244(15.2)$ & $137(15.2)$ & $107(15.3)$ & \\
Total & 1603 & 903 & 700 & \\
\hline
\end{tabular}

Data was collected in São Luís, MA, Brazil, in 2016. Chi-squared test.

Table 3. Propensity score weighting of study variables.

\begin{tabular}{|c|c|c|c|c|}
\hline \multirow[t]{2}{*}{ Variable } & \multicolumn{2}{|c|}{ Difference between standardized means } & \multicolumn{2}{|c|}{ Variance Ratio } \\
\hline & Gross value & *Weighted value & Gross value & ${ }^{* *}$ Weighted value \\
\hline \multicolumn{5}{|l|}{ ATE } \\
\hline Preterm birth & 0.297 & -0.006 & 2.196 & 0.985 \\
\hline Parity & -0.045 & 0.003 & 1.009 & 0.999 \\
\hline Mother's smoking & -0.005 & -0.003 & 0.869 & 0.847 \\
\hline Mother's schooling & 0.335 & 0.007 & 2.686 & 0.968 \\
\hline \multicolumn{5}{|l|}{ Mother's age } \\
\hline Between 20 and 34 years & 0.142 & -0.011 & 0.873 & 1.011 \\
\hline 35 years or older & 0.191 & 0.018 & 1.766 & 1.055 \\
\hline
\end{tabular}

Differences between standardized means and variance ratios. Gross and weighted values. *Values below 0.1 indicate similarity between the groups. ${ }^{* *}$ Values between 0.8 and 1.2 indicate similarity between the groups. ATE: average effect of treatment on the population.

Table 4. Mean effect of cesarean section on the occurrence of mood disorders in male and female adolescents (ATE), weighted by the propensity score (IPW).

\begin{tabular}{lcccc}
\hline & \multicolumn{4}{c}{ Cesarean section vs vaginal birth } \\
\cline { 2 - 5 } & Coefficient & Standard error & P-value & $95 \% \mathrm{Cl}$ \\
\hline Mood disorder & & & & \\
$\quad$ Male & -0.0051 & 0.027 & 0.848 & $-0.057 ; 0.047$ \\
$\quad$ Female & 0.0155 & 0.027 & 0.565 & $-0.037 ; 0.068$ \\
$\quad$ Total & 0.0047 & 0.019 & 0.805 & $-0.033 ; 0.042$ \\
Depressive disorder & & & & \\
$\quad$ Male & -0.0119 & 0.019 & 0.523 & $-0.048 ; 0.025$ \\
$\quad$ Female & -0.0085 & 0.197 & 0.666 & $-0.047 ; 0.030$ \\
$\quad$ Total & -0.0099 & 0.014 & 0.469 & $-0.037 ; 0.017$ \\
Bipolar disorder & & & & \\
$\quad$ Male & 0.0014 & 0.023 & 0.951 & $-0.043 ; 0.046$ \\
$\quad$ Female & 0.0257 & 0.023 & 0.259 & $-0.019 ; 0.070$ \\
$\quad$ Total & 0.0128 & 0.016 & 0.434 & $-0.019 ; 0.045$ \\
\hline
\end{tabular}

Data was collected in São Luís, MA, Brazil, 1997-2016. ATE: average effect of treatment on the population. 
of emergency cesarean birth, which occurs once the delivery process starts, the offspring may benefit from partial exposure to the birth canal and delivery-induced physiological hormonal and immunological changes. This could also explain the lack of association between emergency cesarean sections and the development of depression and bipolar disorder in the literature. In the present study, it was not possible to separate elective and emergency caesarean sections, but we believe it was more likely that most deliveries were by elective cesarean section. Thus, we believe that the lack of association in the present study was due to the better control of confounding factors achieved through the use of robust techniques of causal inference, reducing the influence of spurious associations in the results.

The strengths of this study include the graphical and counterfactual approach with a propensity score weighting estimation method and a DAG theoretical model, which enabled the adjustment for the common causes of exposure and outcome. The M.I.N.I questionnaire, used to verify the presence of mood disorders in adolescents, is a validated and reliable tool for diagnostic purposes (23). No study in the literature has stratified the results by sex nor carried out the analysis of depressive and bipolar disorders individually and combined (herein named "mood disorder" construct). In addition, this is a pioneer study evaluating depression outcomes (without psychotic symptoms).

\section{References}

1. Blustein J, Liu J. Time to consider the risks of caesarean delivery for long term child health. BMJ 2015; 350: 2410, doi: 10.1136/bmj.h2410.

2. Betrán $A P$, Ye J, Moller AB, Zhang J, Gülmezoglu AM, Torloni MR. The increasing trend in caesarean section rates: global, regional and national estimates. Plos One 2016; 11: e0148343, doi: 10.1371/journal.pone.0148343.

3. Cho CE, Norman M. Cesarean section and development of the immune system in the offspring. Am J Obstetr Gynecol 2013; 208: 249-254, doi: 10.1016/j.ajog.2012.08.009.

4. Heijtz RD. Fetal, neonatal, and infant microbiome: perturbations and subsequent effects on brain development and behavior. Semin Fetal Neonatal Med 2016; 21: 410-417, doi: 10.1016/j.siny.2016.04.012.

5. Chen G, Chiang WL, Shu BC, Guo YL, Chiou ST, Chiang TL. Associations of caesarean delivery and the occurrence of neurodevelopmental disorders, asthma or obesity in childhood based on Taiwan birth cohort study. BMJ Open 2017; 7: e017086, doi: 10.1136/bmjopen-2017-017086.

6. Rosenberg KR, Trevathan WR. Evolutionary perspectives on cesarean section. Evolut Med Public Health 2018; 2018: 67-81, doi: 10.1093/emph/eoy006.

7. Goldani HÁ, Bettiol H, Barbieri MA, Silva AA, Agranonik M, Morais MB, et al. Cesarean delivery is associated with an increased risk of obesity in adulthood in a Brazilian birth cohort study. Am J Clin Nutr 2011; 93: 1344-1347, doi: 10.3945/ajen.110.010033.
The limitations of this study comprise the retrospective collection of perinatal data, which may have led to measurement bias (memory) and lack of information on mood disorders among adolescents' relatives and the lack of differentiation between elective and emergency cesarean birth.

The overall increase in the rate of cesarean sections is worrisome and has encouraged research into the possible consequences of delivery procedure on early determinants of physical and mental health in adulthood (1). Our study demonstrated that cesarean birth delivery was not associated with the development of mood disorders in adolescents, which may be due to the non-existence of this association and to the presence of unknown familial genetic and environmental confounders.

\section{Acknowledgments}

The authors thank the institutions Federal University of Maranhão, Ribeirão Preto School of Medicine, and Federal University of Pelotas that allowed the present study to be conducted and thank the following institutions that financed the study: FAPESP (São Paulo State Research Support Foundation, number 400943/2013-1), DECIT (Department of Science and Technology of the Ministry of Heath), and CAPES (Coordination of the Improvement of Higher Education Personnel).

8. Kuhle S, Tong OS, Woolcott CG. Association between caesarean section and childhood obesity: a systematic review and meta-analysis. Obes Rev 2015; 16: 295-303, doi: 10.1111/obr.12267.

9. Magnus $M C$, Håberg SE, Stigum $H$, Nafstad $P$, London SJ, Vangen $S$, et al. et al. Delivery by cesarean section and early childhood respiratory symptoms and disorders: the Norwegian mother and child cohort study. Am J Epidemiol 2011; 174: 1275-1285, doi: 10.1093/aje/kwr242.

10. Cardwell CR, Stene LC, Joner G, Cinek O, Svensson J, Goldacre MJ. et al. Caesarean section is associated with an increased risk of childhood-onset type 1 diabetes mellitus: a meta-analysis of observational studies. Diabetologia 2008; 51: 726-735, doi: 10.1007/s00125-008-0941-z.

11. Glasson EJ, Bower C, Petterson B, Klerk N, Chaney G, Hallmayer JF. Perinatal factors and the development of autism: a population study. Arch Gen Psychiatry 2004; 61: 618-627, doi: 10.1001/archpsyc.61.6.618.

12. Curran EA, O'Neill SM, Cryan JF, Kenny LC, Dinan TG, Khashan AS. et al. Research review: birth by caesarean section and development of autism spectrum disorder and attention-deficit/hyperactivity disorder. J Child Psychol Psychiatry 2014; 56: 500-508, doi: 10.1111/jcpp.12351.

13. Chudal R, Sourander A, Polo-Kantola P, Hinkka-Yli-Salomäki S, Lehti V, Sucksdorff D. et al. Perinatal factors and the risk of bipolar disorder in Finland. J Affect Disord 2014; 155: 75-80, doi: 10.1016/j.jad.2013.10.026. 
14. O'Neill SM, Curran EA, Dalman C, Kenny LC, Kearney PM, Clarke G. et al. Birth by caesarean section and the risk of adult psychosis: a population-based cohort study. Schizophr Bull 2015; 42: 633-641, doi: 10.1093/schbul/ sbv152.

15. American Psychiatric Association. Diagnostic and statistical manual of mental disorders: DSM - 5. Porto Alegre: Artmed; 2014.

16. Halfon N, Labelle R, Cohen D, Guilé JM, Breton JJ. Juvenile bipolar disorder and suicidality: a review of the last 10 years of literature. Eur Child Adolesc Psychiatry 2012; 22: 139-151, doi: 10.1007/s00787-012-0328-z.

17. Polanczyk GV, Salum GA, Sugaya LS, Caye A, Rohde LA. Annual research review: a meta-analysis of the worldwide prevalence of mental disorders in children and adolescents. J Child Psychol Psychiatry 2015; 56: 345-365, doi: 10.1111/ jcpp.12381.

18. Craddock N, Forty L. Genetics of affective (mood) disorders. Eur J Human Genet 2006; 14: 660-668, doi: 10.1038/sj. ejhg.5201549.

19. Munhoz TN, Santos IS, Barros AJD, Anselmi L, Barros FC, Matijasevich A. et al. Perinatal and postnatal risk factors for disruptive mood dysregulation disorder at age 11: 2004 Pelotas birth cohort study. J Affect Dis 2017; 215: 263-268, doi: 10.1016/j.jad.2017.03.040.

20. Silva AAM, Coimbra LC, Silva RA, Alves MTS, Lamy Filho F, Lamy ZC. et al. Perinatal health and mother-child health care in the municipality of São Luís, Maranhão State, Brazil. Cad Saude Publica 2001; 17: 1412-1423, doi: 10.1590/ S0102-311X2001000600012.

21. Simões VMF, Batista RFL, Alves MTSSB, Ribeiro CCC, Thomaz EBAF, Carvalho CA, da Silva AAM. Health of adolescents in the 1997/1998 birth cohort in São Luís, Maranhão State, Brazil [in Portuguese]. Cad Saude Publica 2020; 36: e00164519, doi: 10.1590/0102-311x0016 4519.

22. Moretti-Pires RO, Corradi-Webster CM. Adaptation and validation of the alcohol use disorders identification test (AUDIT) for a river population in the Brazilian Amazon. Cad Saude Publica 2011; 27: 497-509, doi: 10.1590/S0102311X2011000300010.

23. Amorim P. Mini international neuropsychiatric interview (MINI): validation of a short structured diagnostic psychiatric interview [in Portuguese]. Braz J Psychiatry 2000; 22: 106115, doi: 10.1590/S1516-44462000000300003.

24. Cortes TR, Faerstein E, Struchiner CJ. Use of causal diagrams in Epidemiology: application to a situation with confounding [in Portuguese]. Cad Saude Publica 2016; 32: e00103115, doi: 10.1590/0102-311X00103115.
25. Textor J, Hardt J, Knüppel S. DAGitty: a graphical tool for analyzing causal diagrams. Epidemiology 2011; 22: 745, doi: 10.1097/EDE.0b013e318225c2be.

26. Pearl J. Causality: models, reasoning and inference. 2. ed. Cambridge: Cambridge University Press; 2009.

27. Pearl J, Glymour M, Jewell N. P. Causal inference in statistics: a primer. John Wiley \& Sons. Chichester, UK; 2016.

28. Rosenbaum PR, Rubin DB. The central role of the propensity score in observational studies for causal effects. Biometrika 1983; 70: 41-55, doi: 10.1093/biomet/70.1.41.

29. Hernán MA, Robins JM. Causal Inference. Boca Raton: Chapman \& Hall/CRC, forthcoming; 2018.

30. Hernan MA, Hernández-Díaz $S$, Werler MM, Mitchell AA. Causal knowledge as a prerequisite for confounding evaluation: an application to birth defects epidemiology. $A m \mathrm{~J}$ Epidemiol 2002; 155: 176-184, doi: 10.1093/aje/155.2.176.

31. Austin C. An Introduction to propensity score methods for reducing the effects of confounding in observational studies. Multivariate Behav Res 2011; 46: 399-424, doi: 10.1080/ 00273171.2011 .568786$.

32. Leite W. Practical Propensity Score Methods Using R. Thousand Oaks, CA: Sage Publishing; 2017.

33. Bain M, Juszczak E, Mclnneny K, Kendell RE. Obstetric complications and affective psychoses: Two case-control studies based on structured obstetric records. $\mathrm{Br} J$ Psychiatry 2000; 176: 523-526, doi: 10.1192/bjp.176.6.523.

34. Orellana JDY, Ribeiro MRC, Barbieri MA, Saraiva MC, Cardoso VC, Bettiol H, et al. Mental disorders in adolescents, youth, and adults in the RPS Birth Cohort Consortium (Ribeirão Preto, Pelotas and São Luís), BrazilCad Saude Publica 2020; 36: e00154319.

35. Pirkola SP, Isometsä E, Suvisaari J, Aro H, Joukamaa M, Poikolainen $\mathrm{K}$, et al. DSM-IV mood-, anxiety- and alcohol use disorders and their comorbidity in the Finnish general population. Soc Psychiatry Psychiatr Epidemiol 2005; 40: 1-10, doi: 10.1007/s00127-005-0848-7.

36. Perälä J, Suvisaari J, Saarni SI, Kuoppasalmi K, Isometsä E, Pirkola S, et al. Lifetime prevalence of psychotic and bipolar I disorders in a general population. Arch Gen Psychiatry 2007; 64: 19-28, doi: 10.1001/archpsyc.64.1.19.

37. Merikangas KR, Akiskal HS, Angst J, Greenberg PE, Hirschfeld RM, Petukhova M. et al. Lifetime and 12-month prevalence of bipolar spectrum disorder in the national comorbidity survey replication. Arch Gen Psychiatry 2007; 64: 543-554, doi: 10.1001/archpsyc.64.5.543.

38. Storksen HT, Eberhard-Gran M, Garthus-Niegel S, Eskild A. Fear of childbirth; the relation to anxiety and depression. Acta Obstet Gynecol Scand 2012; 91: 237-242, doi: 10.1111/j.1600-0412.2011.01323.x. 